\title{
Regime shifts in fish recruitment on the Northeast US Continental Shelf
}

\author{
Charles T. Perretti ${ }^{1, *}$, Michael J. Fogarty ${ }^{1}$, Kevin D. Friedland ${ }^{2}$, Jon A. Hare ${ }^{2}$, \\ Sean M. Lucey ${ }^{1}$, Richard S. McBride ${ }^{1}$, Timothy J. Miller ${ }^{1}$, Ryan E. Morse ${ }^{2}$, \\ Loretta O'Brien ${ }^{1}$, Jose J. Pereira ${ }^{3}$, Laurel A. Smith ${ }^{1}$, Mark J. Wuenschel ${ }^{1}$ \\ ${ }^{1}$ National Marine Fisheries Service (NMFS), 166 Water Street, Woods Hole, MA 02543, USA \\ ${ }^{2}$ NMFS, 28 Tarzwell Drive, Narragansett, RI 02882, USA \\ ${ }^{3}$ NMFS, 212 Rogers Avenue, Milford, CT 06460, USA
}

\begin{abstract}
There is accumulating evidence for decadal-scale regime shifts at the base of the food web on the Northeast US Continental Shelf. However, less evidence exists for regime shifts in fish recruitment success, particularly for synchronized regimes across multiple species. Here, we analyzed stock assessment output and survey data to test for regimes in the recruitment success of 18 commercially important marine species over a $29 \mathrm{yr}$ timespan. We then tested whether recruitment regimes coincide with regimes in the zooplankton community, and whether the abundance of large spawners could explain the patterns in recruitment. We found evidence for 3 decadal-scale recruitment regimes: low recruitment success in the 1980s, high success in the 1990s, and a return to low recruitment success in the 2000s. This general pattern was found in all datasets of recruitment. The abundance of large spawners did not appear to be a broad-scale driver of recruitment success; however, recruitment regimes coincided with regimes in copepod abundance and size structure.
\end{abstract}

KEY WORDS: Fish recruitment $\cdot$ Northeast US shelf - Regime shift $\cdot$ Zooplankton

\section{INTRODUCTION}

Marine ecosystems are known to experience rapid, persistent changes in state known as regime shifts, and there is accumulating evidence for regime shifts on the Northeast US Continental Shelf (NE Shelf). For example, there is evidence for phytoplankton

\footnotetext{
*Corresponding author: charles.perretti@noaa.gov
}

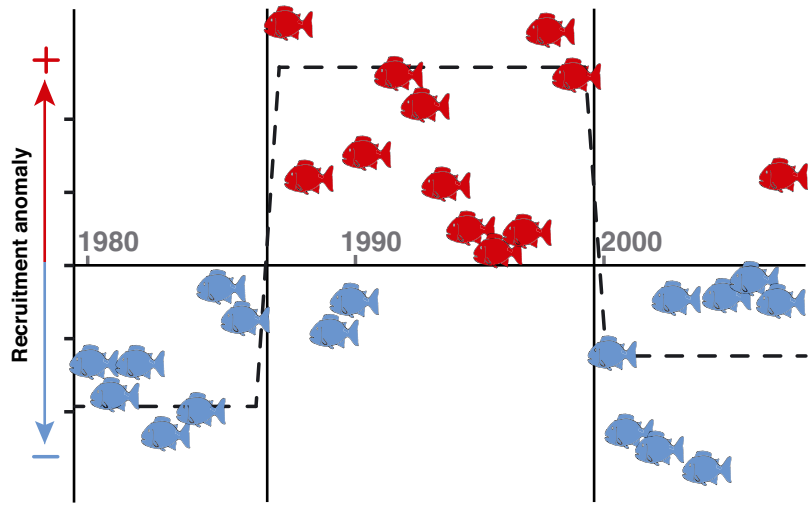

Recruitment success regimes of fish on the Northeast US Continental Shelf.

Graphic: C. Perretti and S. Schüller

productivity regime shifts over the past $30 \mathrm{yr}$ (Kane 2011b, Greene et al. 2013), and regimes in zooplankton biomass and community structure are well documented (Kane 2007, 2011a, 2014, Turner et al. 2011, Greene et al. 2013, Bi et al. 2014, Morse et al. 2017). However, there is less evidence for regime shifts at higher trophic levels, particularly in fish recruitment. As recruitment is often the dominant component of variability in fish populations (Fogarty et al. 1991), and recruitment failures can have dramatic impacts on fisheries (e.g. Ljunggren et al. 2010, Whitmore et al. 2013), identifying regimes in fish recruitment is important.

Several studies have searched for synchrony in fish recruitment patterns on the NE Shelf (and more generally, in the Northwest Atlantic), and synchrony in

Outside the USA ๑ The US Government 2017. Open Access under Creative Commons by Attribution Licence. Use, distribution and reproduction are unrestricted. Authors and original publication must be credited.

Publisher: Inter-Research · www.int-res.com 
productivity across stocks was a particular focus in early studies. Although synchrony in recruitment across stocks was initially suggested (Garrod \& Colebrook 1978, Koslow 1984), follow-up analyses with additional data failed to find synchrony (Cohen et al. 1991, Myers et al. 1995). More recently, in an analysis of 12 New England groundfish stocks, Brodziak \& O'Brien (2005) found significantly positive recruitment anomalies in several years, with 1987 being the most positive anomaly, and significantly negative anomalies in 2000 to 2001. In the Gulf of Maine, Pershing et al. (2005) found several statistically significant relationships between individual fish stocks, zooplankton abundance, and the North Atlantic Oscillation (NAO), with high zooplankton abundance regimes beginning in the late 1980 s, and low abundance beginning in the early 2000s. Similarly, Mountain \& Kane (2010) found evidence for a high abundance zooplankton regime beginning around 1990, and ending in the early 2000s. Together, these studies suggest that fish may exhibit regime-like productivity shifts in response to broad-scale environmental forcing, and on the NE Shelf in particular, a regime shift may have occurred in the late 1980s and the early 2000 s.

In the North Sea, changes in the zooplankton community have been linked to regime-like dynamics in Atlantic cod recruitment (Beaugrand et al. 2003), and a suite of biological and physical variables exhibited regime dynamics in the late 1980s and potentially the late 1990s (Weijerman et al. 2005). Similarly, in the North Pacific, zooplankton regime shifts related to climate forcing have been linked to recruitment regimes in groundfish and salmon (Hare \& Mantua 2000). The connection between zooplankton and the survival of young fish is a classic research topic with zooplankton phenology, community composition, and total abundance all potentially playing a role (Hjort 1914, 1926, Cushing 1974, 1990, Lasker 1978, 1981, Houde 1987). On the NE Shelf, zooplankton abundance has been shown to impact growth rates of some larval fish (Buckley \& Durbin 2006), although the impact of zooplankton on recruitment is often conflated by other co-factors (e.g. Friedland et al. 2015).

Here, we build on earlier analyses centered on individual species (e.g. Mountain \& Kane 2010, Richards et al. 2016) by using a multivariate approach that aims to identify regimes in fish recruitment per unit spawning stock biomass (a measure of recruitment success) and their underlying drivers. Using stock assessments and survey data, we test for coherent regime shifts in recruitment success of 18 species on the NE Shelf over a 29 yr timespan. To our knowledge, this represents the most extensive analysis of regimes in fish recruitment on the NE Shelf, both in number of species analyzed and timespan covered. We then investigate linkages between recruitment regimes, demographic structure, and the zooplankton community.

\section{MATERIALS AND METHODS}

\section{Data sources}

We estimated recruitment success using both stock assessment output and direct observations from the Northeast Fisheries Science Center (NEFSC) bottom trawl survey. For the stock assessments, spawner biomass and recruit abundance $(R)$ was obtained for all stocks in which they were available (23 stocks, 18 species, Table 1). Spawning stock biomass (SSB) was lagged according to the age-at-recruitment $\left(r_{i}\right.$ Table 1$)$ and we used recruit abundance in year $t$ per spawner biomass in year $t-1\left(R_{t} / \mathrm{SSB}_{t-\mathrm{r}}\right)$ as a metric of recruitment survival success (similar results were obtained using $\left.\log _{\mathrm{e}}\left(R_{t} / \mathrm{SSB}_{t-r}\right)\right)$. Stock-recruitment model residuals provide an alternative metric of recruitment success; however, previous studies have found model selection criteria are often unable to identify the correct stock-recruitment model under simulated conditions (de Valpine \& Hastings 2002, Zhou 2007). As a result, stock-recruitment residuals could obscure patterns of recruitment if the residuals are driven by model misspecification. Therefore, we chose to use the relatively simple measure of recruits produced per spawner biomass as our metric of recruitment.

The range of years differs across stock assessments depending on data availability and the date of the last completed assessment. Therefore, we examined the full set of 23 stocks (18 species) with joint information available from 1986 to 2008. We also analyzed the set of 13 stocks (11 species) for which information was available from 1980 to 2008. We restricted our observations to 2008 in these 2 datasets because recruitment estimates from terminal years of a stock assessment are often the most uncertain and most likely to change in future assessments. Further, a number of stocks in the Northeast exhibit a 'retrospective pattern' in which convergence of estimates may take several years and more recent years are particularly unreliable (Legault 2008).

A number of different age-structured models provide the foundation for the stock assessments (Table 1). Although these models differ in form and 
Table 1. Description of all stock assessments used in the analysis. Stock areas are single unit (Unit), Gulf of Maine (GOM), Georges Bank (GB), Mid-Atlantic Bight (MAB), Southern New England (SNE), and Cape Cod (CC). Assessment methods are Age Structured Assessment Program (ASAP), Virtual Population Analysis (VPA), Statistical Catch At Length (SCALE), and Statistical Catch at Age (SCA)

\begin{tabular}{|c|c|c|c|c|c|}
\hline Scientific name & Common name & $\begin{array}{l}\text { Stock } \\
\text { area }\end{array}$ & $\begin{array}{l}\text { Assessment } \\
\text { timespan }\end{array}$ & $\begin{array}{c}\text { Recruitment } \\
\text { age } r\end{array}$ & $\begin{array}{l}\text { Assessment } \\
\text { method }\end{array}$ \\
\hline Sebastes fasciatus & Acadian redfish & Unit & $1913-2014$ & 1 & ASAP \\
\hline Hippoglossoides platessoides & American plaice & GOM/GB & $1980-2014$ & 1 & VPA \\
\hline \multirow[t]{2}{*}{ Gadus morhua } & \multirow[t]{2}{*}{ Atlantic cod } & GB & $1978-2011$ & 1 & ASAP \\
\hline & & GOM & $1982-2014$ & 1 & ASAP \\
\hline Clupea harengus & Atlantic herring & Unit & $1965-2011$ & 1 & ASAP \\
\hline Scomber scombrus & Atlantic mackerel & Unit & $1962-2009$ & 1 & ASAP \\
\hline Lophius americanus & Goosefish & Unit & 1980-2009 & 1 & SCALE \\
\hline \multirow[t]{2}{*}{ Melanogrammus aeglefinus } & \multirow[t]{2}{*}{ Haddock } & GB & $1960-2014$ & 1 & VPA \\
\hline & & GOM & $1977-2014$ & 1 & ASAP \\
\hline Pollachius virens & Pollock & Unit & 1970-2014 & 1 & ASAP \\
\hline Stenotomus chrysops & Scup & Unit & $1984-2010$ & 0 & ASAP \\
\hline Merluccius bilinearis & Silver hake & Unit & 1973-2009 & 1 & ASAP \\
\hline Morone saxatilis & Striped bass & Unit & $1982-2012$ & 1 & $\mathrm{SCA}$ \\
\hline Paralichthys dentatus & Summer flounder & Unit & $1982-2012$ & 0 & ASAP \\
\hline Lopholatilus chamaeleonticeps & Tilefish & Unit & $1971-2012$ & 1 & ASAP \\
\hline Urophycis tenuis & White hake & Unit & $1963-2014$ & 1 & ASAP \\
\hline \multirow[t]{2}{*}{ Pseudopleuronectes americanus } & \multirow[t]{2}{*}{ Winter flounder } & SNE/MAB & $1981-2014$ & 1 & ASAP \\
\hline & & GB & $1982-2014$ & 1 & VPA \\
\hline Glyptocephalus cynoglossus & Witch flounder & Unit & $1982-2014$ & 3 & VPA \\
\hline Anarhichas lupus & Atlantic wolffish & Unit & 1968-2014 & 1 & SCALE \\
\hline \multirow[t]{3}{*}{ Limanda ferruginea } & \multirow[t]{3}{*}{ Yellowtail flounder } & GB & $1973-2012$ & 1 & VPA \\
\hline & & SNE/MAB & $1973-2014$ & 1 & ASAP \\
\hline & & $\mathrm{CC} / \mathrm{GOM}$ & $1985-2014$ & 1 & VPA \\
\hline
\end{tabular}

assumptions, they all impose a structural filter on the data that influences the output (Brooks \& Deroba 2015, Dickey-Collas et al. 2015). Accordingly, we repeated our analysis using NEFSC bottom trawl survey data (15 species), which is independent of these structural assumptions. Stock assessments and survey data both have unique strengths and weaknesses; however, by including both sources of information we hope to increase the robustness of our results.

The NEFSC bottom trawl survey spans the Northeast shelf from the Gulf of Maine to Cape Hatteras in both the spring and fall. The survey gear, sampling procedures and design details have been described by Azarovitz (1981) and Smith (2002). Because 3 different research vessels and gears were employed during the time period analyzed, we applied vessel and gear conversion coefficients derived using pairedtow calibration studies (Byrne \& Fogarty 1985, Byrne \& Forrester 1991, Miller et al. 2010). We also restricted the timespan to match the stock assessment time series as closely as possible (1980 to 2007). The survey series ends in 2007 because the NEFSC bottom trawl survey switched vessels in 2009 and lengthspecific catchability coefficients have not been estimated for many of the species in this analysis.
Therefore, for all species, our last observations of recruitment occurred in 2008, which corresponds to the 2007 year-class.

For the survey data, only a sample of fish are aged. Therefore we identified age- 1 fish as those with length less than the expected length of an age-2 fish. To find the expected length-at-age, we used a generalized linear model where length was modeled as a Poisson random variable and age as the predictor variable:

$$
\ln [E(L \mid A)]=\mathrm{b}_{0}+\mathrm{b}_{1} A
$$

where $L$ is length $(\mathrm{cm})$ and $A$ is age (yr), and the expected value of length conditional on age is a linear function of age on a log scale (i.e. a Poisson loglinear model with parameters $\mathrm{b}_{0}$ and $\mathrm{b}_{1}$ ). The Poisson model was chosen because length is recorded to the nearest $\mathrm{cm}$ in the survey and is strictly positive. Overdispersion was checked using the 'dispersiontest' function in the AER package in R, and was not found in any species. The age- 1 threshold was then used to calculate a small and large fish index (numbers below and above the threshold, respectively) each year. As an additional check, we defined size thresholds based on the 20th percentile of the length 
distribution across all years and found identical regime shift change points to the Poisson modeled results (see Fig. S1 in the Supplement at www.intres.com/articles/suppl/m574p001_supp.pdf).

Biomass was calculated using length-weight relationships directly from the survey data. Following Wigley et al. (2003), the length-weight relationship was modeled as:

$$
\ln W=\ln a+b \ln L
$$

where $W$ is weight $(\mathrm{kg}), L$ is length $(\mathrm{cm})$, and $a$ and $b$ are parameters fit via linear regression. The ratio of small fish numbers of the following year to larger fish biomass in the current year was used as a proxy for the assessment-based recruitment success index. The fall and spring recruitment success anomalies were averaged to provide an annual index of recruitment success. To reduce the number of missing observations, recruitment calculations were performed on the species level rather than the stock level. In doing so, we were able to include all species found in the stock assessment analysis except striped bass Morone saxatilis, tilefish Lopholatilus chamaeleonticeps and wolfish Anarhichas lupus, because each are poorly sampled by the trawl and had at least 3 years in which small fish were not captured.

\section{Regime shift detection}

Regime shifts were detected using chronological clustering (Legendre \& Legendre 2012), an algorithm designed to identify discontinuities in spatial and temporal data. Chronological clustering is flexible in that it does not impose a functional form on the relationship between the dependent variable (e.g. recruitment) and explanatory variable (e.g. time). Among other applications, it has been applied to multi-species time series of zooplankton (Legendre et al. 1985), spatial distributions of plants (Tuomisto \& Ruokolainen 1994), and marine ecosystem time series in Northwest Europe (Weijerman et al. 2005).

We implemented chronological clustering using multivariate regression trees (MRT, Breiman et al. 1984, De'ath 2002, Borcard et al. 2011) via the 'rpart' package and the 'rpart' function in R using the default parameter values (Therneau et al. 2015). The clustering algorithm partitions the multivariate recruitment time series into temporal groups (i.e. regimes) where the groups are chosen to minimize the sum of squares within the groups (also known as minimizing the impurity measure, De'ath 2002). The sum of squares within a regime is given by:

$$
\sum_{i, j}\left(x_{i, j}-\bar{x}_{j}\right)^{2}
$$

where $x_{i, j}$ is the recruitment measure for species or stock $j$ in year $i$ of the regime, and $\bar{x}_{j}$ is the mean of species or stock $j$ in the regime. The sum is over all species and stocks in the dataset; therefore, all species are used simultaneously to determine the regime partitions. The final partitions are selected using $k$ fold cross-validation prediction error ( $k=10$ here). Chronological clustering is performed by using time as the explanatory variable in the MRT, which enforces a temporal contiguity constraint.

\section{Sensitivity analysis}

The chronological clustering algorithm uses information on all stocks simultaneously when determining the regime change points. Therefore, we estimated the sensitivity of each regime change point to the stocks included in the analysis by running the chronological clustering algorithm on a sample of stocks ranging from a single stock to all available stocks. We used all possible combinations of stocks for a given sample size up to a maximum of 10000 combinations. The probability of detecting a change point for a given sample size was calculated as the proportion of runs in which a change point ( \pm 1 year) was detected. For example, for the 2001 change point, we calculated the proportion of runs in which a change point was detected in 2000, 2001, or 2002.

We also investigated the uncertainty associated with each change point using a bootstrap analysis. For each dataset, the bootstrap simulation randomly selected species with replacement to generate a bootstrapped dataset with the same number of time series as the original dataset. The change point algorithm was then applied to each bootstrapped dataset and the change points were recorded. This procedure was repeated 1000 times for each dataset. The distribution of change point years provides a measure of the uncertainty associated with the change point year.

\section{Copepod indices}

Copepod abundance data from 1977 through 2013 was obtained from a long-term ecosystem monitoring program of the NE Shelf (Marine Resources Monitoring, Assessment, and Prediction, from 1977 to 1987, and Ecosystem Monitoring Program (EcoMon) from 1994 to the present). Samples were collected using 
oblique tows of bongo nets with a mesh size of $333 \mu \mathrm{m}$ (Kane 2007). This mesh size does not capture the smallest copepod species; however, it provides a long-term shelf-wide index of the most common large copepod taxa. For each copepod taxa, a seasonally stratified area-weighted abundance (i.e. per net tow) was calculated. The samples were post-stratified to one-degree bins and copepod indices were calculated for separate geographic regions following Lucey \& Fogarty (2013) to test whether particular regions (i.e. Gulf of Maine, Georges Bank, and the Mid-Atlantic Bight) were more likely to drive recruitment regimes.

We examined 2 previously developed indices of the copepod community: total abundance and size structure (Ecosystem Assessment Program 2011). For the total abundance index, annual abundance anomalies for the combined top 5 most abundant copepod taxa, consisting of Calanus finmarchicus, Pseudocalanus spp., Centropages typicus, Temora longicornis, and Metridia lucens, were calculated for each geographic region. Abundances of all included taxa were summed for a given year and an annual $z$-score was computed.

The size structure index was calculated as the difference between the mean of the anomalies of the small-bodied copepods and the anomaly of a largebodied copepod (i.e. small copepod mean anomaly large copepod anomaly). The small-bodied copepods were Centropages typicus, Pseudocalanus spp., T. longicornis, and Centropages hamatus, and the large-bodied copepod was Calanus finmarchicus. There is a seasonal cycle in copepod community structure, and the timing of the survey has changed over time. Therefore, anomalies were computed following the Kane (2007) method, which accounts for variability in the timing of sample collection. First, a cubic spline function is fit to the daily abundance for each taxon using data from the entire time series (see Fig. S2 in the Supplement). This provides an estimate of the expected abundance on any day of the year. The anomaly is calculated as the difference between the observed and the expected abundance given by the spline function. These anomalies are then averaged over each year to obtain an annual anomaly.

\section{Age truncation}

Emerging evidence suggests that the progeny of older, experienced spawners may have higher survival rates than younger (particularly first-time) spawners (see Jakobsen et al. 2016 and contributions therein). Therefore, the removal of older fish may be an important driver of recruit survival, particularly in the Northwest Atlantic where several stocks have experienced fishery-induced changes in size and age structure (Wigley 1999, Hutchings 2005, McBride et al. 2013). Using abundance-at-age data from all available age-structured stock assessments (19 stocks), we tested whether changes in the abundance of older fish explained changes in recruit survival. We identified old fish as those older than the 25th percentile of the age distribution of their stock (similar results were obtained when using the 20th percentile), where the age distribution was built using data over the timespan in which all stocks were assessed (1986 to 2008). We calculated the abundance anomaly of the old fish group in each year, and tested for change points corresponding to those found in the recruit survival index.

\section{RESULTS}

We found evidence for 3 recruitment regimes: an initial regime of low recruitment success through the late 1980s, a switch to high recruitment success through the 1990s, and finally a return to low recruitment success through the early 2000s (Fig. 1). Recruitment success regime change points were similar in all datasets - the shift to high recruitment success occurs in 1987 in all datasets that extend back to 1980. The shift to low recruitment occurs in 2000 in both the 1980 to 2008 and 1986 to 2008 datasets. The similarity in change points found in the survey dataset and the assessment datasets suggests that both datasets are tracking the same recruitment processes, and that the recruitment regimes are unlikely to be driven solely by the assessment modeling process.

For all recruitment datasets, the mean coefficient of variation $(\mathrm{CV})$ of recruit abundance was higher than that of spawner biomass (Table 2), as might be expected given the narrower age range of recruits and high variability of the recruitment process. Spawner biomass was generally low through the 1990s, then rebounded in the early 2000s after several years of high recruitment in the late 1990s (see Figs. S3, S4 \& S5 in the Supplement) and, for some stocks, decreased fishing mortality.

The probability of detecting a change point increased steadily as more stocks were added to the analysis (Fig. 2). Less than half of the species exhibited a statistically detectable regime shift when analyzed in isolation (represented by the left-most point in each panel of Fig. 2). When 5 species were in- 

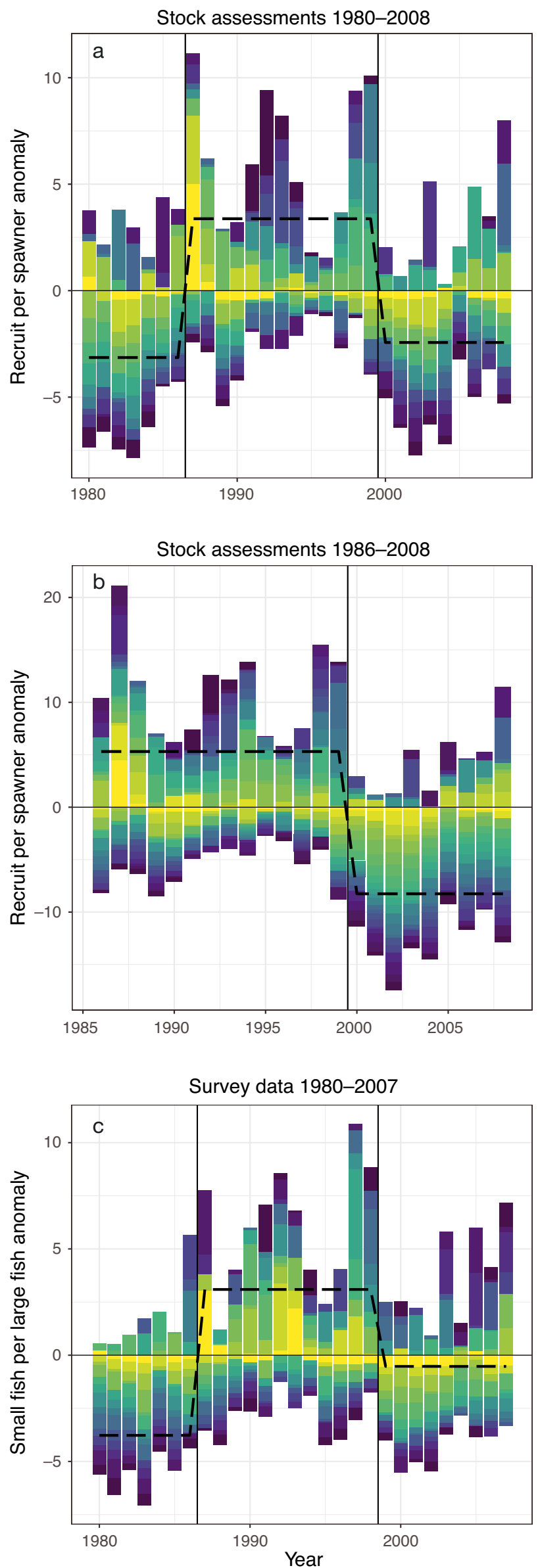

Acadian Redfish

Cod GB

Haddock GB

Haddock GOM

Herring

Mackerel

Pollock

Silver Hake

Tilefish

White Hake GB GOM

Wolfish

Yellowtail Flounder GB

Yellowtail Flounder SNE MAB

Acadian Redfish

American Plaice

Cod GB

Cod GOM

Goosefish

Haddock GB

Haddock GOM

Herring

Mackerel

Pollock

Scup

Silver Hake

Striped Bass

Summer Flounder

Tilefish

White Hake GB GOM

Winter Flounder GB

Winter Flounder SNE MAB

Witch Flounder

Wolffish

Yellowtail Flounder CC GOM

Yellowtail Flounder GB

Yellowtail Flounder SNE MAB
Acadian redfish

American plaice

Atlantic cod

Atlantic herring

Atlantic mackerel

Goosefish

Haddock

Pollock

Scup

Silver hake

Summer flounder

White hake

Winter flounde

Witch flounder

Yellowtail flounder
Fig. 1. Stacked bar chart of recruit per spawner anomalies for each recruitment dataset. (a) Stock assessments from 1980 to 2008, (b) stock assessments from 1986 to 2008, (c) survey data from 1980 to 2007. The vertical lines are the regime shift change points as determined by the chronological clustering algorithm. The dashed line is the average total annual anomaly within each regime. See

Table 1 for abbreviations 
Table 2. Coefficient of variation (CV) of recruit abundance and spawner biomass for all recruitment datasets

\begin{tabular}{|lcc|}
\hline Recruitment dataset & $\begin{array}{c}\text { Recruit } \\
\text { abundance } \\
\text { CV }\end{array}$ & $\begin{array}{c}\text { Spawner } \\
\text { biomass } \\
\text { CV }\end{array}$ \\
\hline Stock assessments 1980-2008 & 1.02 & 0.56 \\
Stock assessments 1986-2008 & 0.80 & 0.38 \\
Survey data 1980-2007 & 0.98 & 0.62 \\
\hline
\end{tabular}

cluded, the probability of detecting a regime shift increased to approximately $75 \%$; at 10 species, the probability was approximately $80 \%$ in the survey dataset and $95 \%$ in the stock assessment datasets. The 1987 change point was slightly more difficult to detect than the 2000 change point, as illustrated by its lower initial detection probability in all datasets. In general, the probability of detecting a change point in the survey dataset was lower than in the stock assessment datasets through most of the range of species, which is likely due to the greater year-toyear variability of the survey data compared to the stock assessment output.

In the bootstrap analysis, for all datasets, the modes of the bootstrap distribution corresponded to the observed change point years of the real datasets (i.e. 1987 and 2000 in the assessment datasets, and 1987 and 1999 in the survey datasets, see Fig. S6 in the Supplement). There was lower uncertainty in the stock assessment datasets, where at least $70 \%$ of the bootstrap runs had the same change point as the real dataset, as compared to the survey dataset, while in the survey dataset approximately 60 and $45 \%$ of runs exhibited the 1987 and 1999 change points, respectively.

The proportion of large fish (our proxy for age truncation) began high, declined through the 1980s, was low through the 1990s, and increased through the 2000s (Fig. 3). The hypothesis underlying the agetruncation mechanism is that old fish are expected to have proportionally higher relative fecundity, higher quality eggs, and spawn over longer periods that are more likely to coincide with optimal conditions for larval survival. Therefore, low abundance of old fish should correspond to low recruitment success. However, in contrast to this, the period of low old fish abundance (the 1990s) corresponded to a period of high recruitment, and similarly, the period of high old fish abundance (2000s) coincided with a period of low recruitment success. Therefore, it seems unlikely that age truncation is driving patterns of recruitment in the stocks examined.

Copepod abundance regimes were similar to the recruitment regimes, particularly that of copepod community size structure (Fig. 4, see Fig. S7 in the Supplement). Overall, copepod abundance was below average in the 1980s, switched to above average in the 1990s, and returned to below average in the 2000s. The earliest and longest high abundance regime occurred in the Gulf of Maine, beginning in 1991 and ending in 2001. On Georges Bank, the high

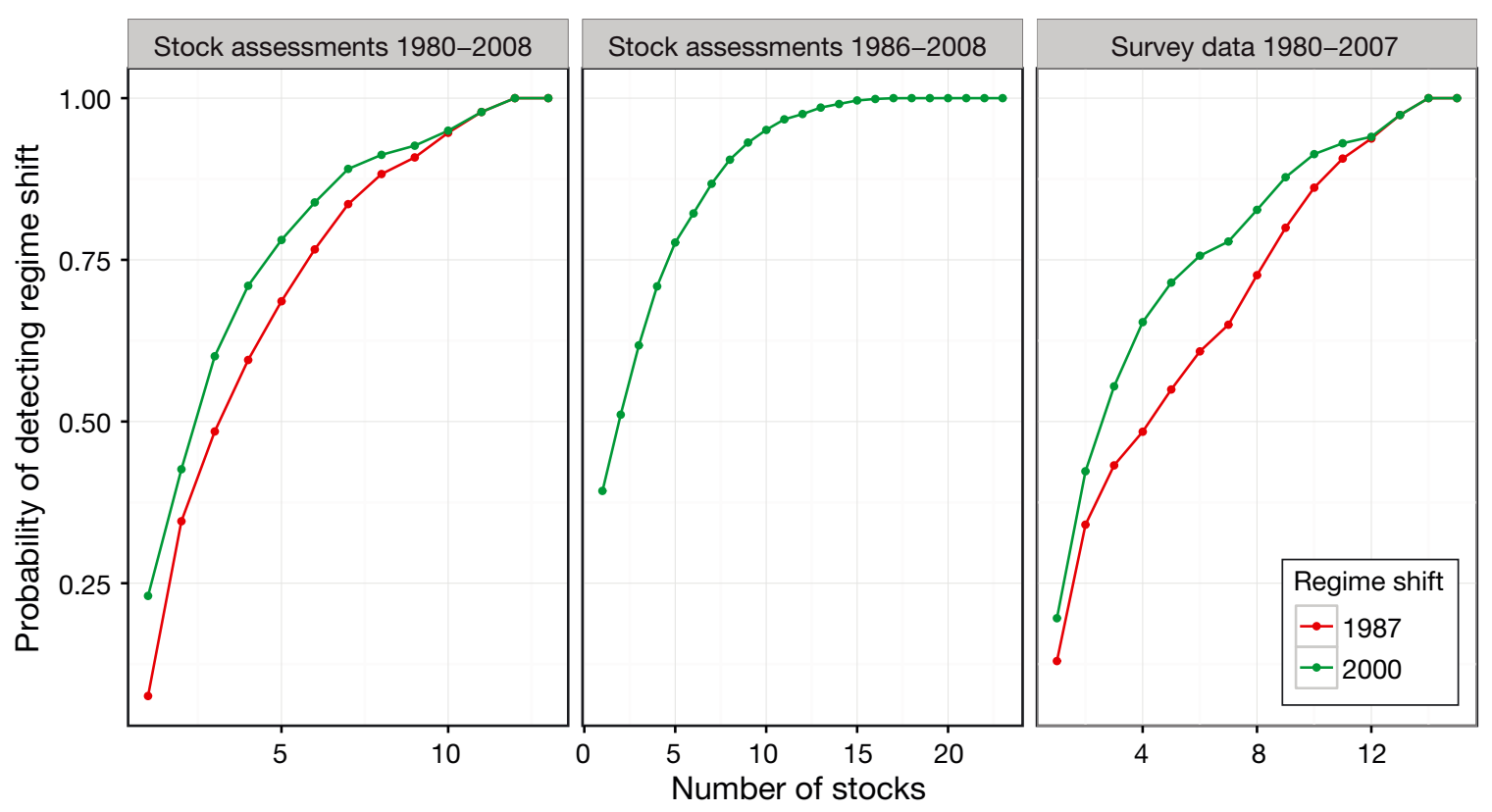

Fig. 2. Change point sensitivity analysis for each recruitment dataset 


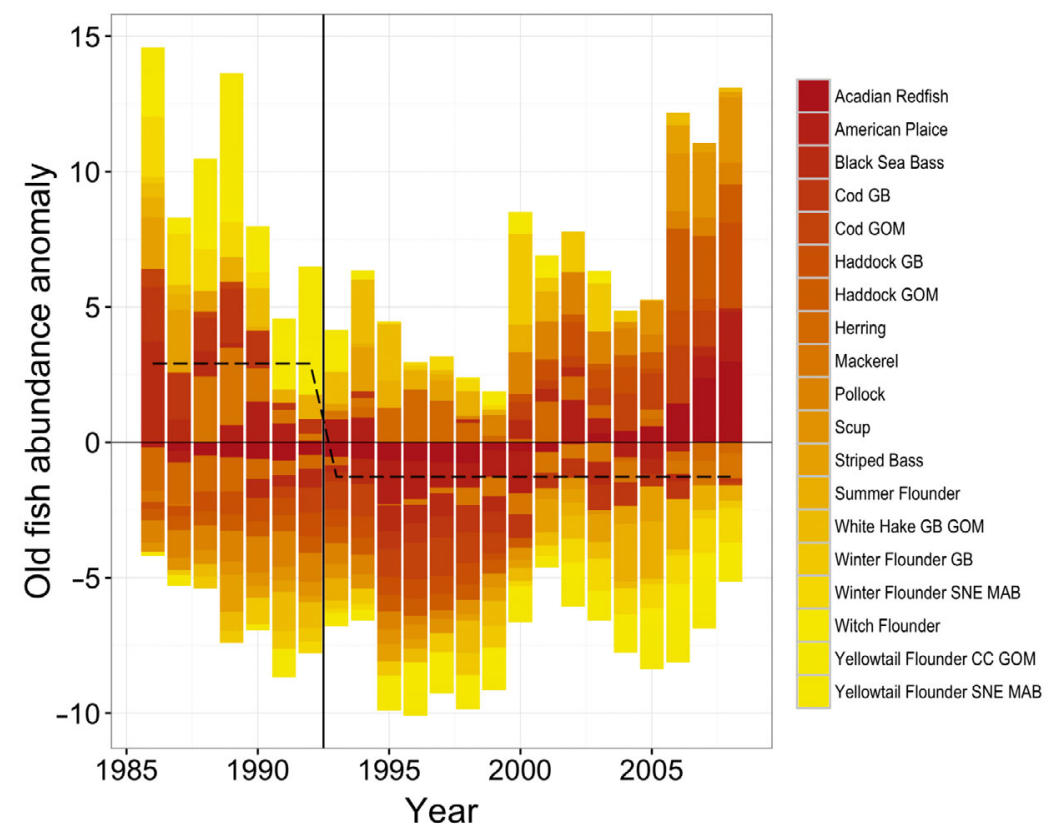

Fig. 3. Stacked bar chart of old fish abundance anomaly for each species with abundance-at-age data, chronological clustering breakpoint (vertical line), and average total annual anomaly within each regime (dashed line). See Table 1 for abbreviations

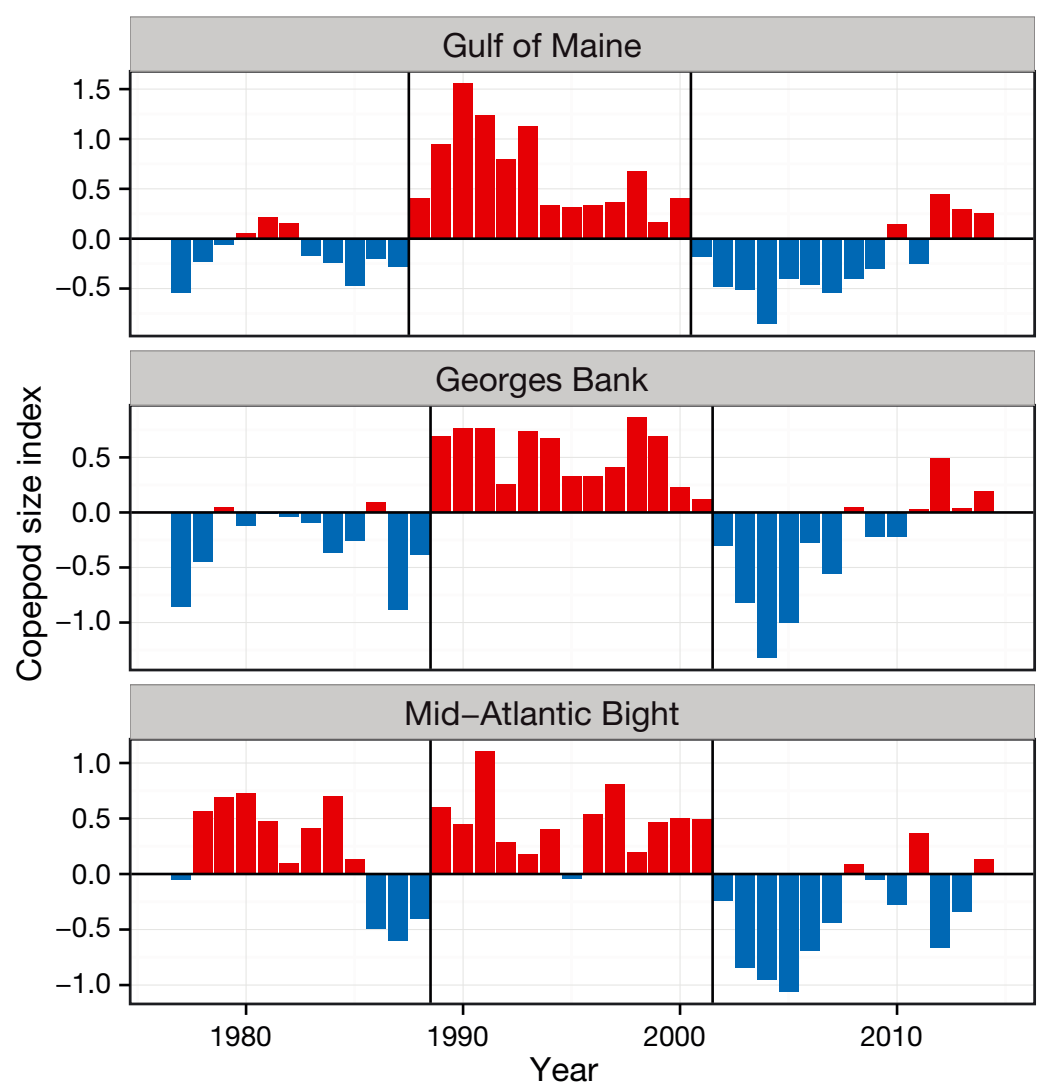

Fig. 4. Copepod size index (small copepod anomaly - large copepod anomaly) time series. Each bar represents the average annual anomaly, and vertical lines denote regime change points abundance regime spanned from 1996 to 2003, and in the Mid-Atlantic Bight, it spanned from 1994 to 2001. In addition, 2 of the 3 most recent years exhibited positive anomalies, suggesting a return to a high abundance regime.

Even more closely mirroring the recruitment regimes were the copepod size regimes (Fig. 4). The early 1980s were dominated by largebodied copepods (i.e. Calanus finmarchicus), then in the late 1980s, there was a shift to small-bodied copepods (e.g. Pseudocalanus spp.). The small copepod regime persisted until 2000 in the Gulf of Maine and 2001 in Georges Bank and the MidAtlantic Bight, after which the system switched back to a large copepod regime. The large copepod regime then persisted until 2010, but similar to copepod abundance, recently appears to have switched back to a small copepod regime.

\section{DISCUSSION}

Using stock assessment output, trawl survey data, and a long-term zooplankton survey, we found evidence for regimes in recruitment success in fishes on the NE Shelf, which broadly coincide with changes in the copepod community. Our results build on previous work that found regimes across lower trophic levels on the NE Shelf emanating from changes in ocean circulation (e.g. Pershing et al. 2005, Mountain \& Kane 2010, Greene et al. 2013), specifically linked to changes in Arctic climate (Greene \& Pershing 2007, Greene et al. 2008). Here, we find that regime dynamics appear to impact higher trophic levels as well.

Several potential mechanisms could explain the link between regimes in fish recruitment and regimes at lower trophic levels. Increased zooplankton abundance, particularly of key prey of larval fish, could directly lead to increased larval growth and decreased 
mortality (i.e. the stage-duration hypothesis, Houde 1987). For example, on Georges Bank, an increase in Pseudocalanus spp. during the late 1990s has been linked to increased larval growth rates in Atlantic cod and haddock (Buckley \& Durbin 2006). Similarly, in the Gulf of St. Lawrence, the recruitment success of Atlantic mackerel has been linked to the abundance of preferred copepod nauplii (Castonguay et al. 2008).

An alternative explanation is that increased primary production led to increased benthic flux which led to increased benthic forage for adult groundfish (Townsend \& Cammen 1988). This increased forage base could have led to higher parental condition, higher egg quality, and higher larval survival. Under this mechanism, the observed change in the zooplankton community would have been coincidental, and the real effect on recruitment would be through a benthic pathway. Given that the 1990s were a decade of high phytoplankton production (Kane 2011b), and, in some stocks, there appears to be a link between parental condition and phytoplankton bloom magnitude and phenology (Leaf \& Friedland 2014), this mechanism deserves further investigation.

As mentioned above, although the high recruitment success of the 1990s coincided with a shift in zooplankton community structure and abundance, it also coincided with a period of low spawning stock biomass for many stocks (see Figs. S3, S4 \& S5 in the Supplement). Recruitment success has been shown to increase during periods of low biomass in some stocks (Brodziak et al. 2001), and a link between recruitment and parental condition has been noted elsewhere (Blanchard et al. 2003). Since parental condition may play a role in determining recruitment success, and there is evidence for regimes in parental condition (L. Smith, NEFSC, pers. comm.), the high recruitment regime of the 1990s could have been driven by the combined effect of an increase in preferred copepod prey (particularly small copepods such as Pseudocalanus spp.) and an increase in parental condition due to a decrease in spawning stock biomass. Similarly, the low recruitment regime of the 2000s may have been driven by the increased spawning stock biomass following the high recruitment events of the late 1990s combined with the observed decrease in copepod prey. Further research is needed to understand the interplay of shelf-wide regimes in parental condition, zooplankton abundance, and recruitment success.

While there is evidence for age truncation in several fish populations on the NE Shelf, and there is also evidence that large, old females tend to produce more and higher quality offspring (Berkeley et al. 2004, McBride et al. 2015), we did not find a clear link between recruitment success regimes and age truncation regimes. Rather, trends in age truncation appear to track trends in spawning stock biomass, both of which reached minimum values in the 1990s while recruitment success peaked, although some stocks had already experienced age truncation prior to the 1980s. Given that the high recruitment success of the 1990s occurred while many stocks were truncated, recruitment might have been even higher during the 1990s in the absence of age truncation, and similarly, the low recruitment success of the 1980s and 2000s could have been even lower if the populations had been truncated. In this way, big, old females may be particularly valuable during low productivity regimes. Additionally, despite being truncated, many stocks contained repeat spawners since the maximum age is typically much greater than the age at maturity for species in this region. As repeat spawners are known to spawn more and larger eggs (Palakovich Carr \& Kaufman 2009) of higher quality (Kamler 2005) over a longer period (Fitzhugh et al. 2012), this may have provided a buffering effect despite the absence of the oldest individuals.

Although regimes are often difficult to detect in any single stock, once stocks are pooled together the regimes become increasingly clear. The difficulty in identifying regimes in individual stocks is somewhat expected, since each stock is subject to its own sources of variability and sampling error. This highlights the value of a multi-species meta-analytic approach for identifying broad scale ecosystem changes, while also highlighting the importance of stock-specific studies to illuminate remaining sources of variability. In this regard, a multi-species analysis such as this provides ecosystem context for single species analyses. This context is important, because if productivity shifts are unrecognized or ignored, particularly during periods of reduced productivity, risk to populations may be underestimated. However, if productivity shifts are recognized, managers can adjust harvest levels as they deem necessary.

Acknowledgements. We thank the many scientists and field workers who collected and compiled the data of the NEFSC bottom trawl and EcoMon surveys. We thank the scientists and assessment authors who analyzed the data and produced the stock assessment output used here. We also thank 3 anonymous reviewers for providing helpful comments on an earlier version of this manuscript. 


\section{LITERATURE CITED}

Azarovitz T (1981) A brief historical review of the Woods Hole Laboratory trawl survey time series. In: Doubleday WG, Rivard D (eds) Bottom trawl surveys. Can Spec Publ Fish Aquat Sci, Vol 58. Department of Fisheries and Oceans, Ottawa, p 62-67

Beaugrand G, Brander KM, Alistair Lindley J, Souissi S, Reid PC (2003) Plankton effect on cod recruitment in the North Sea. Nature 426:661-664

Berkeley SA, Chapman C, Sogard SM (2004) Maternal age as a determinant of larval growth and survival in a marine fish, Sebastes melanops. Ecology 85:1258-1264

Bi H, Ji R, Liu H, Jo YH, Hare JA (2014) Decadal changes in zooplankton of the Northeast U.S. continental shelf. PLOS ONE 9:e87720

Blanchard JL, Frank KT, Simon JE (2003) Effects of condition on fecundity and total egg production of eastern Scotian Shelf haddock (Melanogrammus aeglefinus). Can J Fish Aquat Sci 60:321-332

Borcard D, Gillet F, Legendre P (2011) Numerical ecology with R. Springer Science \& Business Media, New York, NY

Breiman L, Friedman J, Stone CJ, Olshen RA (1984) Classification and regression trees, 1st edn. Chapman and Hall/CRC, Boca Raton, FL

Brodziak J, O'Brien L (2005) Do environmental factors affect recruits per spawner anomalies of New England groundfish? ICES J Mar Sci 62:1394-1407

Brodziak JK, Overholtz WJ, Rago PJ (2001) Does spawning stock affect recruitment of New England groundfish? Can J Fish Aquat Sci 58:306-318

'Brooks EN, Deroba JJ (2015) When 'data' are not data: the pitfalls of post hoc analyses that use stock assessment model output. Can J Fish Aquat Sci 72:634-641

Buckley LJ, Durbin EG (2006) Seasonal and inter-annual trends in the zooplankton prey and growth rate of Atlantic cod (Gadus morhua) and haddock (Melanogrammus aeglefinus) larvae on Georges Bank. Deep Sea Res II 53:2758-2770

Byrne CJ, Fogarty MJ (1985) Comparison of the fishing power of two fisheries research vessels. Northwest Atlantic Fisheries Organization SCR Doc. 85/90

Byrne CJ, Forrester JRS (1991) Relative fishing power of NOAA R/Vs Albatross IV and Delaware II. National Marine Fisheries Service, Woods Hole, MA

Castonguay M, Plourde S, Robert D, Runge JA, Fortier L (2008) Copepod production drives recruitment in a marine fish. Can J Fish Aquat Sci 65:1528-1531

Cohen EB, Mountain DG, O'Boyle R (1991) Local-scale versus large-scale factors affecting recruitment. Can J Fish Aquat Sci 48:1003-1006

Cushing DH (1974) The natural regulation of fish populations. Harden Jones FR (ed) Sea fisheries research. Elek Science, London, p 399-412

Cushing DH (1990) Plankton production and year-class strength in fish populations: an update of the match/mismatch hypothesis. Adv Mar Biol 26:249-293

de Valpine P, Hastings A (2002) Fitting population models incorporating process noise and observation error. Ecol Monogr 72:57-76

De'ath G (2002) Multivariate regression trees: a new technique for modeling species-environment relationships. Ecology 83:1105-1117

Dickey-Collas M, Hintzen NT, Nash RDM, Schön PJ, Payne MR (2015) Quirky patterns in time-series of estimates of recruitment could be artefacts. ICES J Mar Sci 72: 111-116

Ecosystem Assessment Program (2011) Ecosystem status report for the Northeast U.S. continental shelf Large Marine Ecosystem. US Department of Commerce, Woods Hole, MA

Fitzhugh GR, Shertzer KW, Kellison GT, Wyanski DM (2012) Review of size- and age-dependence in batch spawning: implications for stock assessment of fish species exhibiting indeterminate fecundity. Fish Bull 110:413-425

Fogarty MJ, Sissenwine MP, Cohen EB (1991) Recruitment variability and the dynamics of exploited marine populations. Trends Ecol Evol 6:241-246

Friedland KD, Leaf RT, Kristiansen T, Large SI (2015) Layered effects of parental condition and larval survival on the recruitment of neighboring haddock stocks. Can J Fish Aquat Sci 72:1672-1681

Garrod DJ, Colebrook JM (1978) Biological effects of variability in the North Atlantic Ocean. Rapp P-V Réun Cons Perm Int Explor Mer 173:128-144

Greene CH, Pershing AJ (2007) Climate drives sea change. Science 315:1084-1085

* Greene CH, Pershing AJ, Cronin TM, Ceci N (2008) Arctic climate change and its impacts on the ecology of the North Atlantic. Ecology 89:S24-S38

Greene CH, Meyer-Gutbrod E, Monger BC, McGarry LP and others (2013) Remote climate forcing of decadalscale regime shifts in Northwest Atlantic shelf ecosystems. Limnol Oceanogr 58:803-816

*Hare SR, Mantua NJ (2000) Empirical evidence for North Pacific regime shifts in 1977 and 1989. Prog Oceanogr 47: 103-145

Hjort J (1914) Fluctuations in the great fisheries of northern Europe viewed in the light of biological research. Rapp P-V Réun Cons Int Explor Mer 20:1-228

*Hort J (1926) Fluctuations in the year classes of important food fishes. J Cons Int Explor Mer 1:5-38

Houde E (1987) Fish early life dynamics and recruitment variability. Am Fish Soc Symp 2:17-29

*Hutchings JA (2005) Life history consequences of overexploitation to population recovery in Northwest Atlantic cod (Gadus morhua). Can J Fish Aquat Sci 62:824-832

Jakobsen T, Fogarty MJ, Megrey BA, Moksness E (eds) (2016) Fish reproductive biology: implications for assessment and management, 2nd edn. Wiley-Blackwell, Chichester

Kamler E (2005) Parent-egg-progeny relationships in teleost fishes: an energetics perspective. Rev Fish Biol Fish $15: 399$

Kane J (2007) Zooplankton abundance trends on Georges Bank, 1977-2004. ICES J Mar Sci 64:909-919

Kane J (2011a) Inter-decadal variability of zooplankton abundance in the Middle Atlantic Bight. J Northwest Atl Fish Sci 43:81-92

Kane J (2011b) Multiyear variability of phytoplankton abundance in the Gulf of Maine. ICES J Mar Sci 68:1833-1841

Kane J (2014) Decadal distribution and abundance trends for the late stage copepodites of Pseudocalanus spp. (Copepoda: Calanoida) in the US Northeast continental shelf ecosystem. J Northwest Atl Fish Sci 46:1-13

Koslow JA (1984) Recruitment patterns in Northwest Atlantic fish stocks. Can J Fish Aquat Sci 41:1722-1729

Lasker R (1978) The relations between oceanographic conditions and larval anchovy food in the California Current: identification of factors contributing to recruitment fail- 
ure. Rapp P-V Réun Cons Int Explor Mer 173:212-230

Lasker R (1981) Factors contributing to variable recruitment of the northern anchovy (Engraulis mordax) in the California Current: contrasting years, 1975 through 1978. Rapp P-V Réun Cons Int Explor Mer 178:375-388

Leaf RT, Friedland KD (2014) Autumn bloom phenology and magnitude influence haddock recruitment on Georges Bank. ICES J Mar Sci 71:2017-2025

Legault CM (2008) Report of the Retrospective Working Group, January 14-16, 2008. Northeast Fish Sci Cent Ref Doc 09-01, U.S. Dept. Commerce, Woods Hole, MA

Legendre P, Legendre LFJ (2012) Numerical ecology, Vol 24, 3rd edn. Elsevier, Amsterdam

Legendre P, Dallot S, Legendre L (1985) Succession of species within a community: chronological clustering, with applications to marine and freshwater zooplankton. Am Nat 125:257-288

Ljunggren L, Sandström A, Bergström U, Mattila J and others (2010) Recruitment failure of coastal predatory fish in the Baltic Sea coincident with an offshore ecosystem regime shift. ICES J Mar Sci 67:1587-1595

Lucey SM, Fogarty MJ (2013) Operational fisheries in New England: linking current fishing patterns to proposed ecological production units. Fish Res 141:3-12

McBride RS, Vidal TE, Cadrin SX (2013) Changes in size and age at maturity of the northern stock of tilefish (Lopholatilus chamaeleonticeps) after a period of overfishing. Fish Bull 111:161-175

McBride RS, Somarakis S, Fitzhugh GR, Albert A and others (2015) Energy acquisition and allocation to egg production in relation to fish reproductive strategies. Fish Fish 16:23-57

Miller TJ, Das C, Politis PJ, Miller AS and others (2010) Estimation of Albatross IV to Henry B. Bigelow Calibration Factors. Northeast Fish Sci Cent Ref Doc 10-05 U.S. Department of Commerce, Woods Hole, MA

Morse RE, Friedland KD, Tommasi D, Stock C, Nye J (2017) Distinct zooplankton regime shift patterns across ecoregions of the U.S. Northeast continental shelf Large Marine Ecosystem. J Mar Syst 165:77-91

Mountain DG, Kane J (2010) Major changes in the Georges Bank ecosystem, 1980s to the 1990s. Mar Ecol Prog Ser 398:81-91

Myers RA, Barrowman NJ, Thompson KR (1995) Synchrony of recruitment across the North Atlantic: an update. (Or, 'now you see it, now you don't!'). ICES J Mar Sci 52:103-110

Editorial responsibility: Sigrun Jónasdóttir, Charlottenlund, Denmark
Palakovich Carr J, Kaufman L (2009) Estimating the importance of maternal age, size, and spawning experience to recruitment of Atlantic cod (Gadus morhua). Biol Conserv 142:477-487

Pershing AJ, Greene CH, Jossi JW, O'Brien L, Brodziak JKT, Bailey BA (2005) Interdecadal variability in the Gulf of Maine zooplankton community, with potential impacts on fish recruitment. ICES J Mar Sci 62:1511-1523

'Richards RA, O'Reilly JE, Hyde KJW (2016) Use of satellite data to identify critical periods for early life survival of northern shrimp in the Gulf of Maine. Fish Oceanogr 25: 306-319

Smith TD (2002) The Woods Hole bottom-trawl resource survey: development of fisheries-independent multispecies monitoring. ICES Mar Sci Symp 215:474-482

Therneau T, Atkinson B, Ripley B (2015) rpart: recursive partitioning and regression trees. R package version 4.19. http://CRAN.R-project.org/package=rpart

Townsend DW, Cammen LM (1988) Potential importance of the timing of spring plankton blooms to benthic-pelagic coupling and recruitment of juvenile demersal fishes. Biol Oceanogr 5:215-228

Tuomisto H, Ruokolainen K (1994) Distribution of Pteridophyta and Melastomataceae along an edaphic gradient in an Amazonian rain forest. J Veg Sci 5:25-34

* Turner JT, Borkman DG, Libby PS (2011) Zooplankton trends in Massachusetts Bay, USA: 1998-2008. J Plankton Res 33:1066-1080

Weijerman M, Lindeboom H, Zuur AF (2005) Regime shifts in marine ecosystems of the North Sea and Wadden Sea. Mar Ecol Prog Ser 298:21-39

Whitmore K, Richards A, Carloni J, Hunter M, Hawk M, Drew K (2013) Assessment report for the Gulf of Maine northern shrimp. Atlantic States Marine Fisheries Commission's Northern Shrimp Technical Committee, Arlington, VA

Wigley SE (1999) Effects of first-time spawners on stockrecruitment relationships for two groundfish species. J Northwest Atl Fish Sci 25:215-218

Wigley SE, McBride HM, McHugh NJ (2003) Length-weight relationships for 74 fish species collected during NEFSC research vessel bottom trawl surveys, 1992-99. NOAA Tech Memo NMFS NE 171

Zhou S (2007) Discriminating alternative stock-recruitment models and evaluating uncertainty in model structure. Fish Res 86:268-279

Submitted: November 21, 2016; Accepted: May 6, 2017 Proofs received from author(s): June 21, 2017 